\title{
Quality of Life After Sentinel Lymph Node Biopsy or Axillary Lymph Node Dissection in Stage I/II Breast Cancer Patients: A Prospective Longitudinal Study
}

\author{
Jan Kootstra, MD, ${ }^{1}$ Josette E. H. M. Hoekstra-Weebers, PhD, ${ }^{2,3,4}$ \\ Hans Rietman, MD, PhD,${ }^{5}$ Jaap de Vries, MD, PhD, ${ }^{1}$ Peter Baas, MD, PhD, ${ }^{6}$ \\ Jan H. B. Geertzen, MD, PhD, ${ }^{4,7}$ and Harald J. Hoekstra, MD, PhD ${ }^{1}$

\footnotetext{
${ }^{1}$ Department of Surgical Oncology, University Medical Center Groningen, University of Groningen, P.O. Box 30.001, 9700 RB Groningen, The Netherlands

${ }^{2}$ Wenkebach Institute, University Medical Center Groningen, University of Groningen, Groningen, The Netherlands ${ }^{3}$ Comprehensive Cancer Center North-Netherlands, Groningen, The Netherlands The Netherlands

${ }^{5}$ Roessingh Research and Development, Enschede, The Netherlands

${ }^{6}$ Department of Surgery, Martini Hospital, Groningen, The Netherlands

${ }^{7}$ Center for Rehabilitation, University Medical Center Groningen, University of Groningen, Groningen, The Netherlands
} \\ ${ }^{4}$ SHARE, Graduade School for Health Research, University Medical Center Groningen, University of Groningen, Groningen,
}

\footnotetext{
Published online July 3, 2008.

Address correspondence and reprint requests to: Harald $\mathbf{J}$. Hoekstra, MD, PhD; E-mail: h.j.hoekstra@chir.umcg.nl Published by Springer Science+Business Media, LLC @ The Author(s) 2008
}

Background: Breast cancer patients' quality of life (QoL) after surgery has been reported to improve significantly over time. Little is known about QoL recovery after sentinel lymph node biopsy (SLNB) in comparison to axillary lymph node dissection (ALND).

Methods: 175 of 195 stage I/II breast cancer patients completed the EORTC QLQ-C30: one day before surgery (T0) and after 6 (T1), 26 (T2), 52 (T3) and 104 (T4) weeks. Of these, 54 patients underwent SLNB, 56 SLNB + ALND and 65 ALND. General linear models and paired $T$-tests between $\mathrm{T} 0-\mathrm{T} 4$ and $\mathrm{T} 1-\mathrm{T} 4$ were computed. Complications, radiotherapy and systemic therapy were added to the model.

Results: Significant time effects were found on physical, role and emotional functioning. Physical and role functioning decreased between T0 and T1. At T4, SLNB patients' functioning had increased to their T0 level; ALND (+/-SLNB) patients' functioning had increased, but had not improved to T0 level. Emotional functioning increased linearly between T0 and T4. At T4, emotional functioning was significantly higher in all groups as compared with T0. No significant group or interaction (time $\times$ group) effects were found. Complications and chemotherapy had a significant negative effect on role, emotional and cognitive functioning. Complications had a significant effect on social functioning also. Effect sizes varied between 0.00 and 0.06 .

Conclusion: Two years post surgery, breast cancer patients' QoL is comparable to that shortly before surgery. Women rated their emotional functioning as even better. SLNB is not associated with a better QoL than ALND. However, undergoing systemic therapy and/or experiencing complications affects QoL negatively.

Key Words: Breast - Cancer-Quality of life - SLNB - ALND - Stage I-II. 
94.3 per 100,000 . With a mortality of 26.0 per 100,000 , breast cancer is the most frequent cause of death in women. ${ }^{2}$ However, due to breast cancer screening and new adjuvant systemic and/or hormone therapies survival after breast cancer has improved by $7-11 \%$ over the past few years. ${ }^{3-5}$ Consequently, the group of breast cancer survivors is gradually increasing, making it increasingly important to gain insight into their quality of life.

In general, the quality of life of breast cancer survivors is reported to be good and comparable with that of the normal population. ${ }^{6-15}$ However, $20-30 \%$ of breast cancer survivors continue to have problems adjusting or experience a decreased quality of life. ${ }^{16}$ It is therefore essential to identify risk factors for poorer functioning.

As far as treatment characteristics are concerned, it has been reported that women who underwent a mastectomy ${ }^{17}$ and/or (adjuvant) systemic therapy had a lower quality of life than women who did not receive these therapies. ${ }^{6,18-21}$ However, other research groups did not find any difference in quality of life between these groups. ${ }^{13,22}$ In addition, adjuvant radiotherapy, particularly to the axilla, was found to be related to functional problems in the arm and shoulder. $^{23}$

In the 1990s, axillary lymph node dissection (ALND) was replaced by sentinel lymph node biopsy (SLNB) in breast cancer patients with a clinically and ultrasound-negative axilla. ${ }^{24,25}$ With the aid of SLNB, it is possible to identify positive axillary lymph nodes in a minimally invasive manner. Nowadays, SLNB is a proven safe surgical method that causes less morbidity than ALND. ${ }^{26-29}$ In about onethird to three-quarters of breast cancer patients, SLNB prevents unnecessary staging dissection of the axillary lymph nodes. ${ }^{30-36}$

Several studies compared quality of life between patients who underwent ALND and women who underwent SLNB. ${ }^{37-43}$ These studies showed that the SLNB women experienced a comparable or better quality of life than the ALND patients. However, these studies had limitations, such as the use of nonvalidated questionnaires, only one postoperative measurement was performed, lack of clarity about the stage of breast cancer in the study population, or obscure information about the level of axillary lymph node dissection. Four of these studies obtained longitudinal data on quality of life and had a prospective design..$^{39,41-43}$ The limitations in these studies were small population size, ${ }^{41}$ or that groups were treated according to the intention-to-treat principle, which implies that the SLNB group also contained SLNB- positive patients who underwent secondary ALND or radiotherapy to the axilla. ${ }^{39,42}$

The aim of the present study was to measure the course of quality of life over a period of 2 years in women with stage I or II breast cancer who underwent SLNB, or SLNB followed by ALND (SLNB + ALND), or ALND. It was assumed that (1) quality of life after treatment for breast cancer would improve over the course of time and (2) that there would be fewer limitations in quality of life postoperatively after SLNB than after SLNB + ALND or ALND. This study formes part of a larger study on functional shoulder complaints after breast cancer treatment. ${ }^{44}$

\section{METHODS}

\section{Patients}

Over a 2-year period, all the women suspected of having stage I or II breast cancer at the University Medical Centre Groningen (UMCG) and the Martini Hospital Groningen (MZ) were informed by the nurse practitioner about and invited to participate in a prospective study on quality of life following breast cancer treatment. Exclusion criteria were distant metastases and pre-existing shoulder complaints that had been treated surgically, with medication or physiotherapy. All the participants gave written informed consent.

The patients filled in the first questionnaire at the hospital on the day before surgery (T0). Postoperative questionnaires were sent to the patients 2 weeks before each follow-up appointment, at 6 weeks (T1), 6 months (T2), 1 year (T3) and 2 years (T4). Questionnaires were filled in at home and returned to us in a stamped addressed envelope, or brought along to the outpatient check-up. The study was approved by the Medical Ethics Committees (METCs) at the two hospitals.

\section{Treatment}

The breast cancer patients underwent SLNB, SLNB + ALND, or ALND. SNLB was conducted as described previously. ${ }^{45}$ When lymph node metastases were found in the SLNB, level I-II ALND was performed within 2 weeks. Surgical treatment consisted of breast-conserving treatment or mastectomy. All the women who underwent breast-conserving treatment received postoperative radiotherapy to the breast. Adjuvant systemic chemotherapy, hormonal 
treatment and/or locoregional radiotherapy was given according to the national guidelines. ${ }^{46}$

\section{Questionnaires}

Quality of life was measured using the EORTCQLQ C-30, developed by the European Organisation in Research and Treatment of Cancer (EORTC) study group. It is a frequently used (nationally and internationally), validated, 30-question cancer-specific health-related questionnaire. ${ }^{47}$ In this study, we analysed the global quality of life score and the five functional scales (physical, role, cognitive, emotional and social). Each item has four answer categories: 1 $=$ not at all, $2=$ a little, $3=$ rather a lot, $4=$ very much. Scores were transformed into a scale from 0 to 100 according to the manual, on which a higher global quality-of-life score and higher functional scores corresponded with better quality of life. ${ }^{48}$

\section{Statistical Analysis}

Descriptive analyses were used to evaluate the study groups. $\chi^{2}$ and $T$-tests were used to compare the women who underwent SLNB to the other two groups (SLNB + ALND and ALND) at T0. A general linear model (GLM) procedure analysed longitudinal time, group (SLNB, SLNB + ALND and ALND) and interaction (time $\times$ group) effects on the EORTCQLQ-C30 subscales. The level of clinical relevance was calculated using the effect size, in which an effect size of $0.20-0.49$ reflected a small clinically relevant difference, an effect size of between $0.50-0.80$ reflected a moderate clinically relevant difference and $>0.80$ reflected a large clinically relevant difference. ${ }^{49}$ To evaluate whether recovery occurred and/or returned to the preoperative level (T0-T4) and whether postoperative recovery was significant (T1-T4), paired $T$-tests were used. A difference of 5-10 points on the qualityof-life subscale of the EORTC-QLQ-C30 meant a small clinically relevant difference, a difference of 10 20 points meant a moderate clinically relevant difference and a difference of $>20$ points meant a large clinically relevant difference. ${ }^{50}$ All the statistical procedures were carried out with SPSS 14. Differences were significant at a $p$ value of 0.05 or smaller.

\section{RESULTS}

Only six patients decided not to participate in the study before their operation. A total of 203 patients filled in the preoperative assessment. The surgical

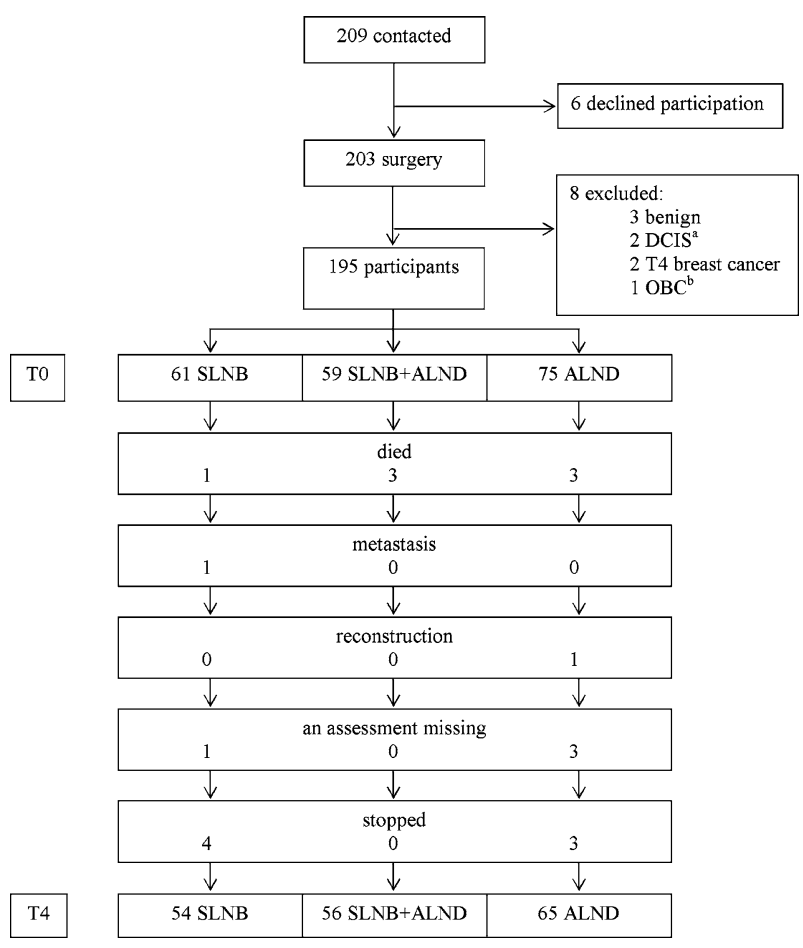

FIG. 1. Flow chart of patients.

findings in eight patients showed that they did not meet the inclusion criteria: three patients had a benign tumour, two patients had ductal carcinoma in situ (DCIS), two patients had a stage 4 tumour and in one patient the primary tumour could not be identified. Consequently, 195 out of 201 eligible patients (response rate $97 \%$ ) were included in the study. It was found that three patients had not fully completed the preoperative questionnaire. At T1, 6 weeks after surgery, $190(97 \%)$ patients returned the questionnaire; at T2, 6 months after surgery, 186 patients returned the questionnaire; at T3, 1 year after surgery, $181(93 \%)$ returned the questionnaire; at T4, 2 years after surgery, $175(90 \%)$ returned the questionnaire. Reasons why the 20 patients $(7$ SLNB, 3 SLNB + ALND, 10 ALND) dropped out were: seven had died from the disease (1 SLNB, 3 SLNB + ALND, 3 ALND), one SLNB patient was found to have distant metastases at T4, one ALND patient was excluded because of breast reconstruction, four patients had missing values (1 SLNB, 3 ALND) and seven patients dropped out because of lack of interest (4 SLNB, 3 ALND) (Fig. 1).

In the remaining group of 175 patients, 110 had undergone SLNB $(63 \%)$. The biopsy had been positive in 56 patients $(51 \%)$ and followed by ALND (Fig. 1). Therefore, the SLNB group was comprised 
TABLE 1. Patient characteristics

\begin{tabular}{|c|c|c|c|c|c|}
\hline Variable & $\operatorname{SLNB}(N=54)$ & $\operatorname{SLNB}+\operatorname{ALND}(N=56)$ & $\operatorname{ALND}(N=65)$ & Test value & $P$ \\
\hline \multicolumn{6}{|l|}{ Age, years } \\
\hline Mean (SD) & $58.1(11.8)$ & $53.75(9.9)$ & $56.5(11.1)$ & $\mathrm{F}=2.19^{d}$ & 0.124 \\
\hline TNM classification $^{a}$ & $N(\%)$ & $N(\%)$ & $N(\%)$ & $\chi^{2}=49.24$ & $<0.001^{e}$ \\
\hline Stage I & $41(76)$ & $8(14)$ & $28(43)$ & & \\
\hline Stage II A & $12(22)$ & $42(75)$ & $25(38)$ & & \\
\hline Stage II B & $1(2)$ & $6(11)$ & $12(19)$ & & \\
\hline Breast surgery & & & & $\chi^{2}=15.28$ & $<0.001$ \\
\hline $\mathrm{BCT}^{b}$ & $37(69)$ & $40(71)$ & $26(40)$ & & \\
\hline Mastectomy & $17(31)$ & $16(29)$ & $39(60)$ & & \\
\hline Complications & & & & $\chi^{2}=9.07$ & $0.011^{f}$ \\
\hline \multirow{2}{*}{\multicolumn{6}{|c|}{ Yes }} \\
\hline & & & & & \\
\hline$>4$ weeks seroma & $2(4)$ & $6(11)$ & $10(16)$ & & \\
\hline Inflammation $^{c}$ & $3(6)$ & $12(21)$ & $8(12)$ & & \\
\hline Radiotherapy & & & & $\chi^{2}=10.63$ & $0.005^{g}$ \\
\hline No & $17(31)$ & $12(21)$ & $32(49)$ & & \\
\hline \multicolumn{6}{|l|}{ Yes } \\
\hline Breast & $37(69)$ & $39(70)$ & $26(40)$ & & \\
\hline Breast and axilla & $0(0)$ & $5(9)$ & $7(11)$ & & \\
\hline Systemic therapy & & & & $\chi^{2}=39.89$ & $<0.001^{h}$ \\
\hline No & $40(74)$ & $8(14)$ & $29(45)$ & & \\
\hline \multicolumn{6}{|l|}{ Yes } \\
\hline Chemo + tamoxifen - & $4(8)$ & $8(14)$ & $13(20)$ & & \\
\hline Chemo + tamoxifen + & $5(9)$ & $21(38)$ & $8(12)$ & & \\
\hline Chemo - tamoxifen + & $5(9)$ & $19(34)$ & $15(23)$ & & \\
\hline
\end{tabular}

${ }^{a} \mathrm{TNM}$, tumour node metastasis; ${ }^{b} \mathrm{BCT}$, breast-conserving therapy; ${ }^{c}$ inflammation treated with antibiotics; ${ }^{d}$ one-way analysis of variance (ANOVA); ${ }^{e}$ patients diagnosed with breast cancer stage I versus IIa and IIb; ${ }^{f}$ no complications versus complications; ${ }^{g}$ no radiotherapy versus radiotherapy; ${ }^{h}$ no systemic therapy versus systemic therapy.

of 54 patients $(31 \%)$, the SLNB + ALND group was comprised of 56 patients (32\%) and the ALND group was comprised of 65 patients $(37 \%)$. Patient characteristics of these 175 women are shown in Table 1. Average age at inclusion was 56 years (standard deviation [SD] 11 years); there was no significant difference in age between the three groups. All lumpectomy patients and 11 mastectomy patients received radiotherapy. Tumour-node-metastasis (TNM) classification, breast surgery, complications, radiotherapy and systemic therapy differed between the groups ( $p$ varied between $<0.001$ to 0.011 ). Therefore, the variables complications (yes/no), systemic therapy (yes/no) and radiotherapy (yes/no) were included in the analyses. A second series of analyses was performed in which radiotherapy was replaced by type of surgery because of overlap between the variables radiotherapy and type of surgery. TNM classification determines the adjuvant treatment protocol (radiotherapy and/or chemotherapy) and was therefore not included.

\section{Quality of Life}

At $\mathrm{T} 0$, there were no significant differences in the scores on the EORTC-QLQ-C30 subscales between the three groups.
Significant time effects were found for physical, role and emotional functioning (Table 2 and Fig. 2). Emotional functioning improved linearly over the course of time; physical and role functioning decreased between $\mathrm{T} 0$ and $\mathrm{T} 1$, increased between $\mathrm{T} 1$ and $\mathrm{T} 2$ and then stabilised. No significant group or time $\times$ group interaction effects were found. The effect sizes of time, group and interaction effects varied from 0.000 for the group effect in global quality of life to 0.060 for the time effect in emotional functioning (Table 2).

Complications and systemic therapy had significant effects on role, emotional and cognitive functioning; complications also had a significant effect on social functioning. The women who had complications and/ or systemic therapy reported poorer functioning than the women without complications and/or systemic therapy. Radiotherapy did not have any significant effect on the EORTC subscales (Table 2), nor did type of breast surgery (data not shown). The effect sizes of these factors varied between 0.000 and 0.061 .

At T4, physical and role functioning were significantly poorer (decrease of between 5-10 points) in the SLNB + ALND and ALND groups than at T0. Emotional functioning at T4 was significantly better in all three groups (increase of between 10-20 points) than at T0. Cognitive functioning was significantly 
TABLE 2. General linear model (GLM)

\begin{tabular}{|c|c|c|c|c|}
\hline Variable & Effect & $F$ & $P$ & Effect size \\
\hline \multirow[t]{6}{*}{ gQoL } & Time & 0.21 & 0.935 & 0.001 \\
\hline & Group $^{a}$ & 0.01 & 0.993 & 0.000 \\
\hline & Interaction $^{b}$ & 1.14 & 0.331 & 0.013 \\
\hline & Complications & 2.81 & 0.095 & 0.016 \\
\hline & Radiotherapy & 0.10 & 0.754 & 0.001 \\
\hline & Systemic therapy & 1.16 & 0.203 & 0.010 \\
\hline \multirow[t]{6}{*}{ Physical } & Time & 3.98 & 0.003 & 0.023 \\
\hline & Group & 0.20 & 0.823 & 0.002 \\
\hline & Interaction & 1.57 & 0.129 & 0.019 \\
\hline & Complications & 0.84 & 0.361 & 0.005 \\
\hline & Radiotherapy & 0.24 & 0.625 & 0.001 \\
\hline & Systemic therapy & 0.57 & 0.435 & 0.003 \\
\hline \multirow[t]{6}{*}{ Role } & Time & 4.26 & 0.002 & 0.025 \\
\hline & Group & 0.53 & 0.588 & 0.006 \\
\hline & Interaction & 1.04 & 0.408 & 0.012 \\
\hline & Complications & 5.85 & 0.017 & 0.033 \\
\hline & Radiotherapy & 0.09 & 0.762 & 0.001 \\
\hline & Systemic therapy & 5.45 & 0.021 & 0.031 \\
\hline \multirow[t]{6}{*}{ Emotional } & Time & 10.66 & $<0.001$ & 0.060 \\
\hline & Group & 0.16 & 0.849 & 0.002 \\
\hline & Interaction & 0.50 & 0.857 & 0.006 \\
\hline & Complications & 10.87 & 0.001 & 0.061 \\
\hline & Radiotherapy & 0.77 & 0.383 & 0.005 \\
\hline & Systemic therapy & 5.00 & 0.027 & 0.029 \\
\hline \multirow[t]{6}{*}{ Cognitive } & Time & 1.35 & 0.284 & 0.008 \\
\hline & Group & 0.46 & 0.633 & 0.005 \\
\hline & Interaction & 1.29 & 0.245 & 0.015 \\
\hline & Complications & 7.38 & 0.007 & 0.042 \\
\hline & Radiotherapy & 0.04 & 0.850 & 0.000 \\
\hline & Systemic therapy & 4.97 & 0.027 & 0.029 \\
\hline \multirow[t]{6}{*}{ Social } & Time & 1.42 & 0.225 & 0.008 \\
\hline & Group & 0.30 & 0.741 & 0.004 \\
\hline & Interaction & 0.44 & 0.899 & 0.005 \\
\hline & Complications & 6.68 & 0.011 & 0.038 \\
\hline & Radiotherapy & 2.94 & 0.089 & 0.017 \\
\hline & Systemic therapy & 3.31 & 0.071 & 0.019 \\
\hline
\end{tabular}

gQoL, global quality of life; ${ }^{a}$ group $=$ SLNB, ALND, or SLNB + ALND; ${ }^{b}$ interaction $=$ effect of time $\times$ group.

The values are in bold since they are significant and facilitate reading.

better (increase of less than 5 points) in the SLNB group than at T0 (Table 3).

In the ALND group, global quality of life (increase of between 10-20 points), emotional and cognitive functioning (increases of between 5-10 points) were significantly higher at T4 than at T1. In the SLNB and ALND groups, physical functioning was significantly better (increase of between $5-10$ points) at T4 than at T1. Role functioning (increase of between 1020 points) and social functioning (increase of less than 5 points in the SNLB group, 5-10 points in the SLNB + ALND group and ALND group) were significantly better at T4 than at T1 (Table 3).

\section{DISCUSSION}

This longitudinal study evaluated the quality of life of women with stage I or II breast cancer who were disease free 24 months after surgery. Comparisons were made between three groups of women who were classified according to the treatment received: SLNB, SLNB + ALND or ALND. It was assumed that quality of life would improve over the course of time and that the women who had undergone SLNB would experience better quality of life than the women who had undergone SLNB + ALND or ALND.

Significant changes over time were found on three subscales of the EORTC. Patterns of change differed between the three subscales. Directly after the operation, women reported their physical and role functioning to be poorer than preoperatively. These improved over the course of time. Changes over time were significant, but the clinical relevance was negligible. At 24 months after the operation, functioning in the women who had undergone ALND $(+/-$ SLNB) was poorer than preoperatively (small clinical difference). This contradicts an earlier study that demonstrated that, after 18 months, the functioning of women who had been treated with SLNB or ALND was comparable to the preoperative level. ${ }^{39}$ However, and in line with that study, we found that, in the women who had undergone SLNB, functioning at 24 months after the operation was comparable with the preoperative situation.

Emotional functioning was at the lowest level preoperatively in all three groups of women, but gradually improved with time. It is not surprising that the women experienced high levels of psychological stress after hearing the diagnosis of breast cancer, in view of the life-threatening nature of the disease. All the women who participated in this study were disease free at 24 months after surgery, which suggests that treatment was successful. This seems to be reflected in their improved emotional functioning. The greatest improvement in emotional functioning was seen at the first check-up, 6 weeks after the operation. The improvement in emotional functioning over the 24 months after surgery was moderate in clinical terms in all three groups. An earlier study did not find any significant improvement in emotional functioning over time. ${ }^{41}$

Overall, there were no differences in quality of life between the women treated with SLNB, SLNB + ALND or ALND. This was in agreement with several other studies. ${ }^{41-43}$ However, our results were discordant with those of the axillary lymphatic mapping against nodal axillary clearance (ALMANAC) trial, in which the women who underwent SLNB experienced better quality of life than the women who underwent ALND. ${ }^{39}$ These results were striking, because the SLNB group in the ALMANAC trial was not homogeneous. Owing to the intention-to-treat 


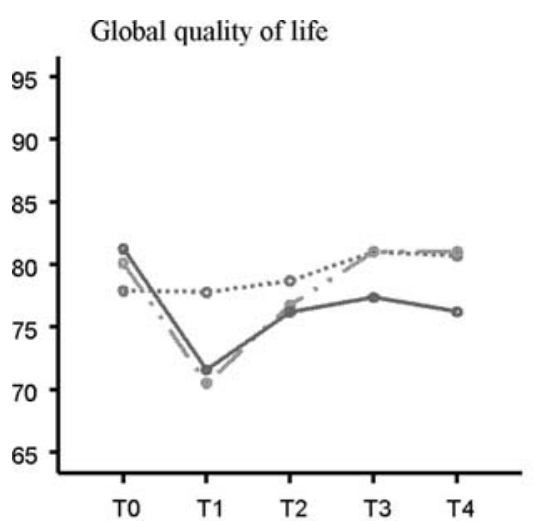

Emotional functioning

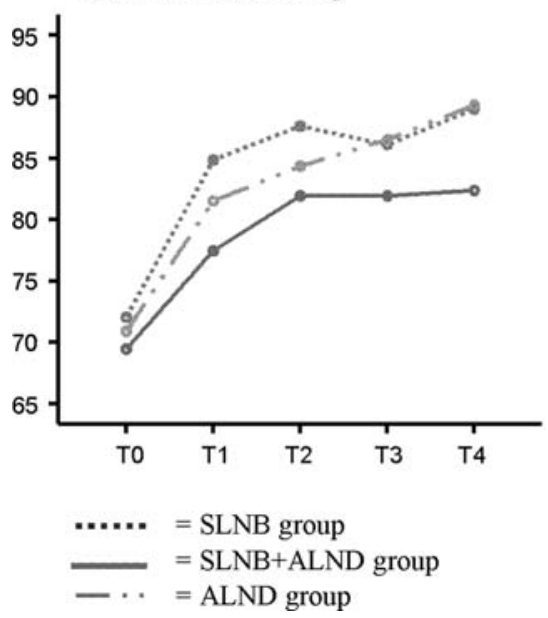

Physical functioning

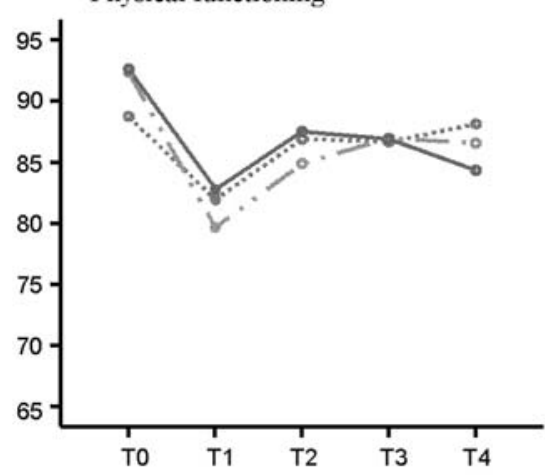

Cognitive functioning

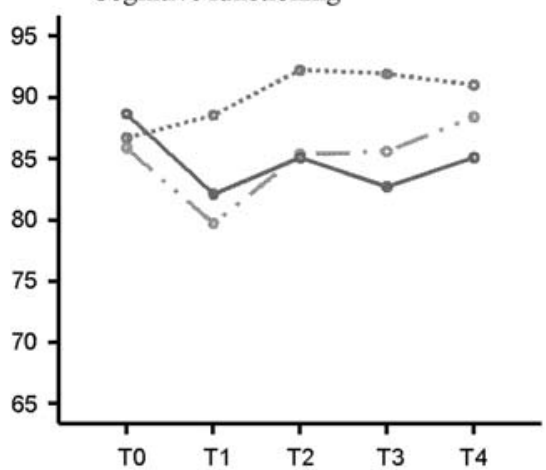

Role functioning

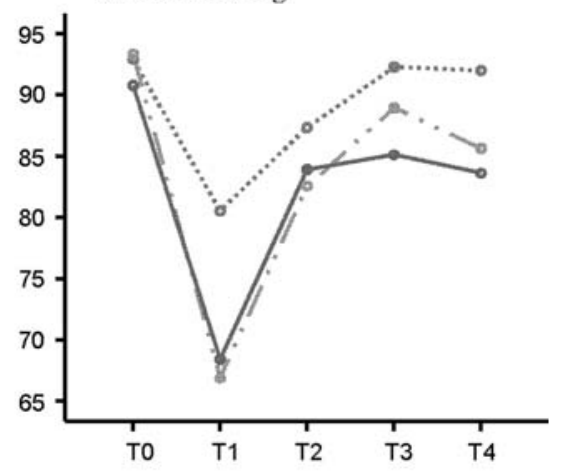

Social functioning

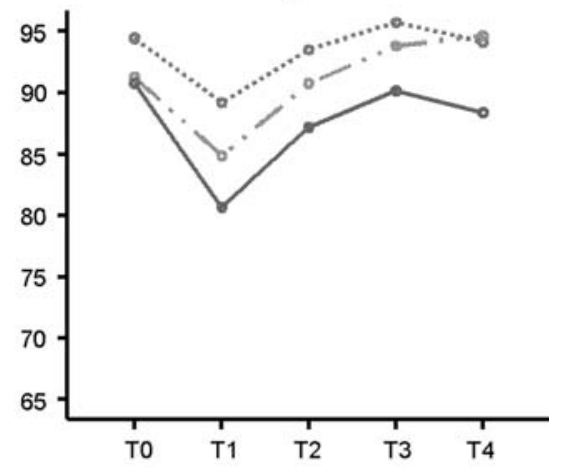

FIG. 2. EORTC-QLQ-C30 global quality of life and the five functional scales.

TABLE 3. Characteristics of the EORTC-QLQ-C30 scales at the different assessment times and paired T-tests

\begin{tabular}{|c|c|c|c|c|c|c|c|c|c|c|c|c|c|}
\hline \multirow[b]{3}{*}{ Variable } & & \multirow{2}{*}{\multicolumn{2}{|c|}{ T0 }} & \multirow{2}{*}{\multicolumn{2}{|c|}{$\mathrm{T} 1$}} & \multirow{2}{*}{\multicolumn{2}{|c|}{$\mathrm{T} 2$}} & \multirow{2}{*}{\multicolumn{2}{|c|}{$\mathrm{T} 3$}} & & & \multicolumn{2}{|c|}{ Paired $T$-test } \\
\hline & & & & & & & & & & \multicolumn{2}{|c|}{$\mathrm{T} 4$} & T0-T4 & $\mathrm{T} 1-\mathrm{T} 4$ \\
\hline & & Mean & SD & Mean & $\mathrm{SD}$ & Mean & $\mathrm{SD}$ & Mean & $\mathrm{SD}$ & Mean & $\mathrm{SD}$ & $P$ & $P$ \\
\hline \multirow[t]{3}{*}{$\mathrm{gQoL}^{a}$} & SLNB & 77.9 & 20.3 & 77.8 & 17.1 & 78.7 & 19.4 & 81.0 & 19.4 & 80.7 & 19.9 & 0.264 & 0.254 \\
\hline & SLNB + ALND & 81.2 & 18.4 & 71.5 & 23.6 & 76.1 & 18.1 & 77.3 & 20.8 & 76.2 & 19.5 & 0.086 & 0.132 \\
\hline & ALND & 80.0 & 15.6 & 70.5 & 18.2 & 76.7 & 17.2 & 81.0 & 20.6 & 81.0 & 17.5 & 0.692 & $<0.001$ \\
\hline \multirow{3}{*}{ Physical } & SLNB & 88.8 & 12.3 & 82.0 & 17.0 & 86.9 & 13.5 & 86.7 & 14.1 & 88.1 & 14.2 & 0.669 & 0.002 \\
\hline & SLNB + ALND & 92.6 & 9.9 & 82.7 & 16.1 & 87.5 & 13.3 & 86.9 & 13.7 & 84.3 & 18.1 & $<0.001$ & 0.540 \\
\hline & ALND & 92.3 & 10.6 & 79.6 & 15.2 & 84.8 & 14.0 & 86.9 & 12.9 & 86.5 & 13.5 & 0.001 & $<0.001$ \\
\hline \multirow[t]{3}{*}{ Role } & SLNB & 92.9 & 18.2 & 80.6 & 22.6 & 87.3 & 19.4 & 92.3 & 16.1 & 92.0 & 14.0 & 0.766 & $<0.001$ \\
\hline & SLNB + ALND & 90.7 & 17.0 & 68.4 & 24.3 & 83.9 & 22.9 & 85.1 & 20.7 & 83.6 & 26.1 & 0.024 & $<0.001$ \\
\hline & ALND & 93.3 & 13.7 & 66.9 & 26.7 & 82.5 & 21.7 & 88.9 & 16.4 & 85.6 & 21.8 & 0.014 & $<\mathbf{0 . 0 0 1}$ \\
\hline \multirow[t]{3}{*}{ Emotional } & SLNB & 72.1 & 20.0 & 84.9 & 17.4 & 87.7 & 15.3 & 86.1 & 15.3 & 89.0 & 19.5 & $<0.001$ & 0.069 \\
\hline & SLNB + ALND & 69.4 & 20.5 & 77.4 & 24.3 & 81.9 & 22.0 & 81.9 & 23.7 & 82.4 & 21.6 & $<0.001$ & 0.067 \\
\hline & ALND & 70.8 & 18.5 & 81.5 & 18.6 & 84.3 & 18.5 & 86.5 & 17.5 & 89.3 & 12.3 & $<0.001$ & 0.003 \\
\hline \multirow[t]{3}{*}{ Cognitive } & SLNB & 86.7 & 15.7 & 88.6 & 14.8 & 92.3 & 14.4 & 92.0 & 14.0 & 91.0 & 13.6 & 0.038 & 0.280 \\
\hline & SLNB + ALND & 88.6 & 14.2 & 82.1 & 17.9 & 85.1 & 19.2 & 82.7 & 19.5 & 85.1 & 17.6 & 0.122 & 0.279 \\
\hline & ALND & 85.8 & 16.7 & 79.7 & 22.1 & 85.3 & 18.9 & 85.6 & 20.8 & 88.4 & 19.5 & 0.297 & $<\mathbf{0 . 0 0 1}$ \\
\hline \multirow[t]{3}{*}{ Social } & SLNB & 94.4 & 10.2 & 89.2 & 18.1 & 93.5 & 13.9 & 95.7 & 9.8 & 94.1 & 13.0 & 0.859 & 0.038 \\
\hline & SLNB + ALND & 90.7 & 18.5 & 80.6 & 22.8 & 87.2 & 19.3 & 90.1 & 19.0 & 88.3 & 20.3 & 0.446 & 0.013 \\
\hline & ALND & 91.2 & 15.0 & 84.8 & 19.2 & 90.7 & 16.1 & 93.8 & 17.3 & 94.6 & 14.4 & 0.129 & $<0.001$ \\
\hline
\end{tabular}

${ }^{a}$ Global quality of life; SD, standard deviation; T0, presurgery; T1, 6 weeks post-surgery; T2, 6 months post-surgery; T3, 12 months postsurgery; T4, 24 months post-surgery.

The values are in bold since they are significant and facilitate reading. 
TABLE 4. Overview of results from longitudinal studies on quality of life comparing $S L N B, S L N B+A L N D$ and ALND in breast cancer patients

\begin{tabular}{|c|c|c|c|c|c|c|c|c|}
\hline \multirow[b]{2}{*}{ Study } & \multirow[b]{2}{*}{ Year } & \multirow[b]{2}{*}{ Design } & \multirow{2}{*}{$\begin{array}{c}\text { Assessment } \\
\text { times }\end{array}$} & \multicolumn{3}{|c|}{ Study groups } & \multirow{2}{*}{$\begin{array}{c}\text { Measurement } \\
\text { instrument }\end{array}$} & \multirow[b]{2}{*}{ Results } \\
\hline & & & & SLNB & $\mathrm{S}+\mathrm{A}^{c}$ & ALND & & \\
\hline $\begin{array}{l}\text { Peintinger } \\
\text { et al. } 41\end{array}$ & 2003 & Prospective & $\begin{array}{l}\text { T0: pre-surgery } \\
\text { T1: post-surgery } \\
\text { T2: 9-12 months }\end{array}$ & 25 & & 31 & $\begin{array}{c}\text { EORTC-QLQ-C30 } \\
\text { (functional scales } \\
\text { and global QoL) }\end{array}$ & $\begin{array}{l}\text { At T1 SLNB patients reported } \\
\text { higher global QoL than at T0. } \\
\text { At T2, both groups reported higher } \\
\text { global QoL than at T0. No other } \\
\text { time differences were found. } \\
\text { No differences between groups } \\
\text { were found. }\end{array}$ \\
\hline $\begin{array}{l}\text { Purushotham } \\
\text { et al. }{ }^{42}\end{array}$ & 2005 & RCT & $\begin{array}{l}\text { T0: post-surgery } \\
\text { T1: } 3 \text { months } \\
\text { T2: } 6 \text { months } \\
\text { T3: } 12 \text { months }\end{array}$ & $134^{a}$ & & 143 & $\begin{array}{l}\text { SF-36 (physical } \\
\text { summary } \\
\text { score, physical } \\
\text { functioning, } \\
\text { vitality) }\end{array}$ & $\begin{array}{l}\text { At T0, SLNB patients reported } \\
\text { higher on physical summary score, } \\
\text { physical functioning and vitality } \\
\text { than ALND patients. No differences } \\
\text { between groups were found at later } \\
\text { follow-up times. }\end{array}$ \\
\hline $\begin{array}{l}\text { Fleissig } \\
\quad \text { et al. }\end{array}$ & 2006 & RCT & $\begin{array}{l}\text { T0: pre-surgery } \\
\text { T1: } 1 \text { months } \\
\text { T2: } 3 \text { months } \\
\text { T3: } 6 \text { months } \\
\text { T4: } 12 \text { months } \\
\text { T5: } 18 \text { months }\end{array}$ & $424^{b}$ & & 405 & $\begin{array}{l}\text { FACT-B }+4 \\
\text { total score, } \\
\text { TOI }\end{array}$ & $\begin{array}{l}\text { SLNB patients reported better QoL } \\
\text { at all postoperative measurement } \\
\text { times and faster recovery to baseline } \\
\text { levels than ALND patients. Decline } \\
\text { in TOI was }>5 \text { points in the ALND } \\
\text { group at T1, T2 and T4. No } \\
\text { clinically relevant change in TOI } \\
\text { was found in the SLNB group. }\end{array}$ \\
\hline $\begin{array}{l}\text { Del Bianco } \\
\text { et al. }{ }^{43}\end{array}$ & 2007 & $\begin{array}{l}\text { Clinical } \\
\text { trial }\end{array}$ & $\begin{array}{l}\text { T0: pre-surgery } \\
\text { T1: } 6 \text { months } \\
\text { T2: } 12 \text { months } \\
\text { T3: } 24 \text { months }\end{array}$ & $159^{a}$ & & 151 & $\begin{array}{l}\text { SF-36 (physical } \\
\text { and mental } \\
\text { summary scores), } \\
\text { PGWB (total } \\
\text { index and anxiety) }\end{array}$ & $\begin{array}{l}\text { No differences between study groups } \\
\text { were found in the physical and } \\
\text { mental summary scores. At T1, } \\
\text { SLNB patients reported a higher } \\
\text { mean PGBW score. At later } \\
\text { measurement times, no significant } \\
\text { differences between groups were } \\
\text { found. At T1, T2 and T3 both } \\
\text { groups reported a decline in } \\
\text { physical summary score compared } \\
\text { to T0. }\end{array}$ \\
\hline $\begin{array}{l}\text { Kootstra } \\
\text { et al. }\end{array}$ & 2008 & Prospective & $\begin{array}{l}\text { T0: pre-surgery } \\
\text { T1: } 6 \text { weeks } \\
\text { T2: } 6 \text { months } \\
\text { T3: } 12 \text { months } \\
\text { T4: } 24 \text { months }\end{array}$ & 54 & 56 & 65 & $\begin{array}{c}\text { EORTC-QLQ-C30 } \\
\text { (functional scales } \\
\text { and global QoL) }\end{array}$ & $\begin{array}{l}\text { Significant time effects were found in } \\
\text { physical, role and emotional } \\
\text { functioning. No significant effects of } \\
\text { treatment groups were found on any } \\
\text { of the scales. At T4, all patients } \\
\text { reported higher emotional } \\
\text { functioning than at T0. At T4, } \\
\text { ALND patients ( }+/- \text { SLNB) } \\
\text { reported lower physical and role } \\
\text { functioning than at T0. }\end{array}$ \\
\hline
\end{tabular}

${ }^{a}$ SLNB group included women treated with SLNB + ALND; ${ }^{b}$ SLNB group included women treated with SLNB + ALND and women treated with SLNB + axillary radiotherapy. ${ }^{c}$ SLNB followed by ALND; RCT, randomised clinical trial; FACT-B + 4, functional assessment cancer therapy breast version 4; TOI, trial outcome index; PGWB, phychological general well-being.

principle, it included women with a positive SLNB, adjuvant ALND or axillary radiotherapy. Furthermore, in the ALMANAC trial, ALND was performed to level III, in contrast with our level II, which may have led to more morbidity and lower quality of life.

Lastly, in our study, we included in our analyses treatment-related variables that were found to differ between the groups. The women who had systemic therapy and/or complications reported poorer quality of life on some of the subscales than those without. It appeared that adjustments in QoL were not so much related to the surgical treatment (SLNB or ALND), but to these treatment-related variables.

Neither radiotherapy nor type of breast surgery had any significant effect on functioning according to the reports made by the women. Earlier publications showed an effect of chemotherapy and an effect of radiotherapy. ${ }^{51-53}$ The literature is largely in line with our finding that there is no advantage in quality of life of lumpectomy over mastectomy. ${ }^{54}$

On the whole it should be noted that comparisons with the literature were hampered by differences in study design and measurement instruments (Table 4). 
Strong points of our study were the high response rate, the use of a validated disease-specific quality-oflife questionnaire combined with a preoperative assessment, multiple postoperative measurements and a longitudinal analysis on different domains of quality of life. A limitation of the study is that no a priori power analysis was performed. Although attrition was low, the size of the groups may not have been large enough to prevent type I or II errors. However, the clinical relevance of all differences found was negligible in size. It is questionable whether analyses using larger groups would reveal clinically relevant differences.

\section{CONCLUSION}

Physical functioning and role functioning in women with stage I or II breast cancer were lowest directly after the operation, but improved with time. Emotional functioning was lowest preoperatively, but continued to improve postoperatively. There were no differences in quality-of-life domains over the course of time between the patients treated with SLNB, SLNB + ALND or ALND. Women with complications or systemic therapy had poorer role, emotional, cognitive and social functioning than their counterparts without these factors.

\section{OPEN ACCESS}

This article is distributed under the terms of the Creative Commons Attribution Noncommercial License which permits any noncommercial use, distribution, and reproduction in any medium, provided the original author(s) and source are credited.

\section{REFERENCES}

1. Jemal A, Siegel R, Ward E, et al. Cancer statistics, 2007. $C A$ Cancer J Clin 2007; 57:43-66.

2. Ferlay J, Autier P, Boniol M, et al. Estimates of the cancer incidence and mortality in Europe in 2006. Ann Oncol 2007; 18:581-92.

3. Early Breast Cancer Trialists' Collaborative Group. Polychemotherapy for early breast cancer: an overview of the randomised trials. Lancet 1998; 352:930-42.

4. Vervoort MM, Draisma G, Fracheboud J, et al. Trends in the usage of adjuvant systemic therapy for breast cancer in the Netherlands and its effect on mortality. Br J Cancer 2004; 91:242-7.

5. Fracheboud J, Otto SJ, van Dijck JA, et al. Decreased rates of advanced breast cancer due to mammography screening in The Netherlands. Br J Cancer 2004; 91:861-7.
6. Ganz PA, Desmond KA, Leedham B, et al. Quality of life in long-term, disease-free survivors of breast cancer: a follow-up study. J Natl Cancer Inst 2002; 94:39-49.

7. Shing-Giwa K, Ganz PA, Petersen L. Quality of life of African-American and white long term breast carcinoma survivors. Cancer 1999; 85:418-26.

8. Casso D, Buist DS, Taplin S. Quality of life of 5-10 year breast cancer survivors diagnosed between age 40 and 49. Health Qual Life Outcome 2004; 2:25.

9. Ganz PA, Greendale GA, Petersen L, et al. Breast cancer in younger women: reproductive and late health effects of treatment. J Clin Oncol 2003; 21:4184-93.

10. Ganz PA, Desmond KA, Leedham B, et al. Quality of life in long-term, disease-free survivors of breast cancer: a follow-up study. J Natl Cancer Ins 2002; 94:39-49.

11. Helgeson VS, Tomich PL. Surviving cancer: a comparison of 5year disease-free breast cancer survivors with healthy women. Psychooncology 2005; 14:307-17.

12. Kendall AR, Mahue-Giangreco M, Carpenter CL, et al. Influence of exercise activity on quality of life in long-term breast cancer survivors. Qual Life Res 2005; 14:361-71.

13. Dorval M, Maunsell E, Deschenes L, et al. Type of mastectomy and quality of life for long term breast carcinoma survivors. Cancer 1998; 83:2130-8.

14. Tomich PL, Helgeson VS. Five years later: a cross-sectional comparison of breast cancer survivors with healthy women. Psychooncology 2002; 11:154-69.

15. Peuckmann V, Ekholm O, Rasmussen NK, et al. Healthrelated quality of life in long-term breast cancer survivors: nationwide survey in Denmark. Breast Cancer Res Trea 2007; 104:39-46.

16. Irvine D, Brown B, Crooks D, et al. Psychosocial adjustment in women with breast cancer. Cancer 1991; 67:1097-117.

17. Engel J, Kerr J, Schlesinger-Raab A, et al. Quality of life following breast-conserving therapy or mastectomy: results of a 5-year prospective study. Breast $J$ 2004; 10:223-31.

18. Ahles TA, Saykin AJ, Furstenberg CT, et al. Quality of life of long-term survivors of breast cancer and lymphoma treated with standard-dose chemotherapy or local therapy. J Clin Oncol 2005; 23:4399-405.

19. Carver CS, Smith RG, Petronis VM, et al. Quality of life among long-term survivors of breast cancer: different types of antecedents predict different classes of outcomes. Psychooncology 2006; 15:749-58.

20. Casso D, Buist DS, Taplin S. Quality of life of 5-10 year breast cancer survivors diagnosed between age 40 and 49. Health Qual Life Outcomes 2004; 2:25.

21. Sugden EM, Rezvani M, Harrison JM, et al. Shoulder movement after the treatment of early stage breast cancer. Clin Oncol (R Coll Radiol) 1998; 10:173-81.

22. Joly F, Espie M, Marty M, et al. Long-term quality of life in premenopausal women with node-negative localized breast cancer treated with or without adjuvant chemotherapy. $\mathrm{Br} J$ Cancer 2000; 83:577-82.

23. Kwan W, Jackson J, Weir LM, et al. Chronic arm morbidity after curative breast cancer treatment: prevalence and impact on quality of life. J Clin Oncol 2002; 20:4242-8.

24. Giuliano AE, Kirgan DM, Guenther JM, et al. Lymphatic mapping and sentinel lymphadenectomy for breast cancer. Ann Surg 1994; 220:391-8.

25. Krag DN, Weaver DL, Alex JC, et al. Surgical resection and radiolocalization of the sentinel lymph node in breast cancer using a gamma probe. Surg Oncol 1993; 2:335-9.

26. Blanchard DK, Donohue JH, Reynolds C, et al. Relapse and morbidity in patients undergoing sentinel lymph node biopsy alone or with axillary dissection for breast cancer. Arch Surg 2003; 138:482-7.

27. Burak WE, Hollenbeck ST, Zervos EE, et al. Sentinel lymph node biopsy results in less postoperative morbidity compared 
with axillary lymph node dissection for breast cancer. $\mathrm{Am} J$ Surg 2002; 183:23-7.

28. Swenson KK, Nissen MJ, Ceronsky C, et al. Comparison of side effects between sentinel lymph node and axillary lymph node dissection for breast cancer. Ann Surg Oncol 2002; 9:74553.

29. Veronesi U, Paganelli G, Viale G, et al. A randomized comparison of sentinel-node biopsy with routine axillary dissection in breast cancer. $N$ Engl J Med 2003; 349:546-53.

30. Krag DN, Anderson SJ, Julian TB, et al. Technical outcomes of sentinel-lymph-node resection and conventional axillarylymph-node dissection in patients with clinically node-negative breast cancer: results from the NSABP B-32 randomised phase III trial. Lancet Oncol 2007; 8:881-8.

31. Wilke LG, McCall LM, Posther KE, et al. Surgical complications associated with sentinel lymph node biopsy: results from a prospective international cooperative group trial. Ann Surg Oncol 2006; 13:491-500.

32. Giuliano AE, Dale PS, Turner RR, et al. Improved axillary staging of breast cancer with sentinel lymphadenectomy. Ann Surg 1995; 222:394-9.

33. Veronesi U, Paganelli G, Galimberti V, et al. Sentinel-node biopsy to avoid axillary dissection in breast cancer with clinically negative lymph-nodes. Lancet 1997 ; 349:1864-7.

34. Ollila DW, Brennan MB, Giuliano AE. The role of intraoperative lymphatic mapping and sentinel lymphadenectomy in the management of patients with breast cancer. Adv Surg 1999; 32:349-64.

35. Schrenk P, Rieger R, Shamiyeh A, et al. Morbidity following sentinel lymph node biopsy versus axillary lymph node dissection for patients with breast carcinoma. Cancer 2000; 88:608-14.

36. Mansel RE, Fallowfield L, Kissin M, et al. Randomized multicenter trial of sentinel node biopsy versus standard axillary treatment in operable breast cancer: the ALMANAC Trial. $J$ Natl Cancer Inst 2006; 98:599-609.

37. Arnaud S, Houvenaeghel G, Moutardier V, et al. Patients' and surgeons' perspectives on axillary surgery for breast cancer. Eur J Surg Oncol 2004; 30:735-43.

38. Barranger E, Dubernard G, Fleurence J, et al. Subjective morbidity and quality of life after sentinel node biopsy and axillary lymph node dissection for breast cancer. J Surg Oncol 2005; 92:17-22.

39. Fleissig A, Fallowfield LJ, Langridge CI, et al. Post-operative arm morbidity and quality of life. Results of the ALMANAC randomised trial comparing sentinel node biopsy with standard axillary treatment in the management of patients with early breast cancer. Breast Cancer Res Treat 2006; 95:279-93.

40. Haid A, Kuehn T, Konstantiniuk P, et al. Shoulder-arm morbidity following axillary dissection and sentinel node only biopsy for breast cancer. Eur J Surg Oncol 2002; 28:705-10.
41. Peintinger F, Reitsamer R, Stranzl H, et al. Comparison of quality of life and arm complaints after axillary lymph node dissection vs sentinel lymph node biopsy in breast cancer patients. Br J Cancer 2003; 89:648-52.

42. Purushotham AD, Upponi S, Klevesath MB, et al. Morbidity after sentinel lymph node biopsy in primary breast cancer: results from a randomized controlled trial. J Clin Oncol 2005; 23:4312-21.

43. Del Bianco P, Zavagno G, Burelli P, et al. Morbidity comparison of sentinel lymph node biopsy versus conventional axillary lymph node dissection for breast cancer patients: Results of the sentinella-GIVOM Italian randomised clinical trial. Eur J Surg Oncol 2008; 34:620-5.

44. Rietman JS, Dijkstra PU, Geertzen JH, et al. Treatment-related upper limb morbidity 1 year after sentinel lymph node biopsy or axillary lymph node dissection for stage I or II breast cancer. Ann Surg Oncol 2004; 11:1018-24.

45. Rutgers EJ, Jansen L, Nieweg OE, et al. Technique of sentinel node biopsy in breast cancer. Eur J Surg Oncol 1998; 24:316-9.

46. http://www.oncoline.nl. Accessed: 23 March 2008.

47. Aaronson NK, Ahmedzai S, Bergman B, et al. The European Organization for Research and Treatment of Cancer QLQC30: a quality-of-life instrument for use in international clinical trials in oncology. $J$ Natl Cancer Inst 1993; 85:365-76.

48. Fayers PM, Aaronson NK, Bjordal K, et al. (1999) The EORTC QLQ-C30 Scoring Manual, 2nd edition. Brussels: European Organization for Research and Treatment of Cancer.

49. Cohen J. (1988) Statistical Power Analysis for the Behavioural Sciences. Hillsdale NJ: Lawrence Erlbaum.

50. Osoba D, Rodrigues G, Myles J, et al. Interpreting the significance of changes in health-related quality-of-life scores. $J$ Clin Oncol 1998; 16:139-44.

51. Hopwood P, Haviland J, Mills J, et al. The impact of age and clinical factors on quality of life in early breast cancer: an analysis of 2208 women recruited to the UK START Trial (Standardisation of Breast Radiotherapy Trial). Breast 2007; 16:241-51.

52. Mols F, Vingerhoets AJ, Coebergh JW, et al. Quality of life among long-term breast cancer survivors: a systematic review. Eur J Cancer 2005; 41:2613-9.

53. Rayan G, Dawson LA, Bezjak A, et al. Prospective comparison of breast pain in patients participating in a randomized trial of breast-conserving surgery and tamoxifen with or without radiotherapy. Int J Radiat Oncol Biol Phys 2003; 55:154-61

54. Ohsumi S, Shimozuma K, Kuroi K, et al. Quality of life of breast cancer patients and types of surgery for breast cancercurrent status and unresolved issues. Breast Cancer 2007; 14:66-73. 